\title{
O ENSINO DE HISTÓRIA ANTIGA EM DEBATE: EDUCAÇÃO COM PLURALIDADE OU TRADICIONALISMO ACADÊMICO? ${ }^{1}$
}

\author{
THE TEACHING OF ANCIENT HISTORY IN DISPUTE: EDUCATION WITH \\ PLURALITY OR ACADEMIC TRADICIONALISM?
}

Matheus Vargas de Souza

\begin{abstract}
RESUMO: Este trabalho tem por objetivo problematizar o debate acerca do ensino de História Antiga na Educação Básica, seja nas tentativas de reduzi-lo, seja em sua defesa, na medida em que se faz necessária uma busca por um denominador comum entre a democratização do conhecimento e a dimensão ideológica que um conteúdo contém. O objetivo central é o de permitir ao aluno uma melhor compreensão do mundo, a partir de uma educação com pluralidade de conhecimentos, mas evitando a noção de conteúdos "universalmente indispensáveis" em detrimento de uma análise verdadeiramente profunda sobre os usos feitos do passado e, no caso do ensino de História, os usos feitos do passado no próprio passado.
\end{abstract}

Palavras-chave: Ensino de história. História Antiga. BNCC.

ABSTRACT: This work has the purpose of to question the discussion about teaching Ancient History in Basic Education, either in attempts of reduce that or in its defense, in that turns necessary a quest by a common denominator between democratization of education and an ideological dimension contained by any discipline. The purpose is to permit for the student a better comprehension of the world, starting with a plural education, but avoiding the notion of matters "universally indispensable" to the detriment of a analysis truly deep about the uses of the past and in the case of the history's teaching the uses of the past in the own past.

Keywords: Teaching of history. Ancient history. BNCC.

\section{Introdução}

Recentemente, sérias discussões sobre a Educação no Brasil se instalaram em diferentes níveis do cenário educacional e dentre todas as discussões insere-se a crescente produção a respeito do Ensino de História.

\footnotetext{
${ }^{1}$ Este texto foi redigido originalmente como avaliação para a disciplina "Seminário de Pesquisa em Ensino de História", ministrada pelo Prof. Dr. Marcelo Magalhães no primeiro semestre de 2017, no curso de Graduação em Licenciatura em História da UNIRIO.

2 Mestrando em História Social pelo PPGH - UNIRIO. Graduado em Licenciatura em História pela UNIRIO. Bolsista CAPES sob orientação da Prof. Dr. Juliana Bastos Marques. E-mail: matheussagrav@gmail.com.
}

História \& Ensino, Londrina, v. 25, n.1, p. 571-588, jan./jun. 2019 
Em meio à elaboração de uma Base Nacional Comum Curricular (BNCC), historiadores de diferentes especialidades estiveram atentos ao tratamento dado a seus conteúdos. Polêmicas se aglomeraram quando da elaboração da primeira versão da Base e um dos pontos essenciais era a presença de histórias entendidas como não diretamente brasileiras no texto, dentre elas a História Antiga. Este trabalho se propõe, desde já, a ser um exercício de reflexão sobre o debate acalorado que exigiu a manutenção dos conteúdos de História Antiga e Medieval, sem, muitas vezes, propor uma problematização das razões desta "presença" de um Mundo Antigo em nossa cultura. Iniciaremos com uma análise da primeira versão da Base, sem, contudo, nos limitarmos a criticá-la, mas, acima de tudo, buscando questionar as críticas talvez pouco construtivas realizadas por alguns intelectuais, dentre eles os das áreas de História Antiga e História Medieval, mantendo o foco àquilo que tange o ensino de História Antiga.

Entre outubro de 2015 e março de 2016, foi disponibilizada para consulta pública a primeira versão da Base Nacional Comum Curricular $\mathrm{BNCC}^{3}$, em meio a um momento político delicado e complexo para a sociedade brasileira, crise política que culminou no processo de impeachment contra Dilma Rousseff. Em sua ducentésima quadragésima primeira página, quando surge o "Componente Curricular História", o texto introdutório se inicia da seguinte maneira:

O Componente Curricular História tem por objetivo viabilizar a compreensão e a problematização dos valores, dos saberes e dos fazeres das pessoas, em variadas espacialidades e temporalidades, em dimensões individual e coletivo (BRASIL,[2015], p. 241).

O texto se propõe, portanto, a permitir à dinâmica educacional um aproveitamento da disciplina História que vai além do aprendizado de conteúdos, quando dá acesso, ao aluno, à problematização e às diversas possibilidades culturais analisáveis. Segue reforçando que "Uma questão

\footnotetext{
3 Ver:

http://www.educacao.mppr.mp.br/arquivos/File/publicacoes/mec/bncc_apresentacao_2015 .pdf .
}

História \& Ensino, Londrina, v. 25, n.1, p. 571-588, jan./jun. 2019 
central para o componente curricular História são os usos das representações sobre o passado, em sua interseção com a interpretação do presente e a construção de expectativas para o futuro" (BRASIL, [2015], p. 241). Poderíamos esperar, com certeza, que os conteúdos tradicionalmente trabalhados fossem reorganizados e debatidos com novas perspectivas, 0 que de fato ocorreu. Ainda assim, houve sérios problemas e uma repercussão violenta que inclui críticas e cartas de repúdio, devido ao tratamento enviesado de temas ${ }^{4}$, à disposição confusa e limitada de outros ${ }^{5}$ e, ainda, a exclusões. É a tais exclusões que vamos nos ater, dado que, neste trabalho, vamos nos concentrar no debate acerca do ensino de História Antiga que se propõe, que se reivindica e que, aparentemente, pouco se problematiza.

Inicialmente, faremos uma análise da primeira versão para podermos compreender o processo do debate. Em meio ao texto introdutório, que comenta raízes identitárias e a proposta de problematizá-las, além da pesquisa entendida como "princípio básico dos processos de construção do conhecimento histórico" (BRASIL, [2015], p. 242), gostaríamos de destacar dois trechos marcantes:

A opção pela ênfase na História do Brasil sustenta-se em quatro fundamentos. Em primeiro lugar, por oferecer um saber significativo para crianças, jovens e adultos, pois conhecer a trajetória histórica brasileira é conhecer a própria trajetória. Em segundo lugar, o reconhecimento de que o saber histórico deve fomentar a curiosidade científica e a familiarização com outras formas de raciocínio, a partir do

\footnotetext{
${ }^{4}$ Para isso recomendamos a nota do GT de História da África da Anpuh, que em resumo critica a associação direta entre a História da África à escravidão, que a BNCC justifica através do discurso do aproveitamento de conteúdos de acordo com a realidade brasileira (sem falar na crítica ao abandono de uma "Antiguidade" e uma "Idade Média" africanas). Disponível em: http://site.anpuh.org/index.php/bncc-historia/item/3322-nota-do-gt-dehistoria-da-africa-da-anpuh-nacional-e-da-associacao-brasileira-de-estudos-africanos-abeafrica-sobre-a-proposta-da-base-nacional-comum-curricular-bncc-para-o-ensino-dehistoria.

${ }^{5}$ Vide o parecer de Marcelo de Souza Magalhães, que comenta o quanto "os objetivos de aprendizagem parecem partes de uma colcha de retalhos" (p. 13) e faz uma análise muito detalhada de todo o currículo, criticando, entre outras coisas, a insistência no estudo do Brasil Colonial por todo o Ensino Fundamental II e a limitação do conteúdo de Brasil Imperial à lógica da escravidão, mostrando, por exemplo, que "identificar origens nos séculos XVI, XVII e XVIII do "povo brasileiro" é, sem dúvida, um anacronismo e um exercício teleológico que deveria ser evitado" (p. 10). Disponível em: http://historiadabncc.mec.gov.br/documentos/relatoriosanaliticos/pareceres/Marcelo_de_S ouza_Magalhaes_HISTORIA.pdf.
} 
acesso a processos e problemas relacionados à constituição e à conformação do Brasil, como país e como nação. [...] É importante destacar que as repetições que se observam em alguns títulos - como nos títulos dos quatro primeiros anos e nos dois últimos do Ensino Fundamental - objetivam apontar para a recursividade que caracteriza a progressão no processo de construção de conhecimentos e de desenvolvimento do estudante (BRASIL, [2015], p. 243).

Destacamos estes trechos porque se referem à estrutura pensada para o Ensino Fundamental, composto por (aqui especificando o Ensino Fundamental II): $6^{\circ}$ ano - Representações, sentidos e significados do tempo histórico; 70 ano - Processos e sujeitos; 80 - Análise de processos históricos; 90 ano - Análise de processos históricos. O que essa primeira tentativa de currículo mínimo apresenta logo em seguida é, na verdade, um rompimento total com a tradição de fundo cronológico do Ensino de História, se observarmos com atenção as propostas para o Ensino Fundamental II. Há uma discussão geral sobre temporalidades no $6^{\circ}$ ano, mas o quadro começa a mostrar suas especificidades mais marcantes quando não aparece menção à História Antiga no $6^{\circ}$ ano, a não ser com uma menção aos egípcios, outra à necessidade de problematizar marcos temporais, no que está incluída a "Idade Antiga", e uma menção à discussão sobre instituições, ideias, acontecimentos e etc, tanto na Idade Antiga e na Medieval, quanto na Idade Moderna e Contemporânea (BRASIL, [2015], p. 251). Fica claro desde o $6^{\circ}$ ano (Representações, sentidos e significados do tempo histórico) que não haverá, necessariamente, uma linha cronológica norteadora dos anos finais do Ensino Fundamental, mas, sim, um processo de aprendizado que buscaria agregar sincronia e diacronia.

O 70 ano (Processos e sujeitos) volta-se exclusivamente para a História a partir do século XVI em diante, com uma ênfase maciça na História do Brasil, incluindo processos como "os deslocamentos forçados de africanos (XVII-XIX), a migração de europeus e asiáticos (XIX-XX) e migrações internas (XIX-XXI)" (BRASIL, [2015], p. 252). O $8^{\circ}$ ano (Análise de processos históricos) trata novamente da História a partir do século XVI, uma vez mais inserindo assuntos relativos à História da África e tratando de 
povos indígenas; defende agora a necessidade do estudo acerca da Revolução Francesa como chave para compreender transformações ocorridas na Europa e, em seguida, aprofundando temas relacionados à História da América e do Brasil; a cronologia segue até o século XIX brasileiro, apenas mencionando pontos como a Independência, a Abdicação e a Cabanagem, inserindo discussões sobre o papel das mulheres e relações de trabalho; há um misto de conteúdos tradicionais esparsos e tópicos para reflexão sobre a sociedade. Por fim, o 90 ano (Análise de processos históricos) traz à tona o século XX, lidando com grandes eventos do século, a exemplo das Guerras Mundiais, como eventos que surgem para complexificar a história brasileira, mas que estão desconectados de suas próprias linhas temporais; quanto ao Brasil do século $\mathrm{XX}$, o período claramente mencionado é o da Era Vargas em diante, tendo a Primeira República uma função talvez mais ilustrativa que propriamente de estudo.

Devemos levar em conta que essa versão se caracteriza por listas de objetivos de aprendizagem. Não podemos deixar de comentar que a primeira BNCC tem seus méritos: uma abordagem que se propõe revolucionária, incluindo discussões mais relacionadas à metalinguagem da historiografia e aos temas tradicionalmente ignorados no Ensino de História. Também não é à toa que, por seu caráter revolucionário, esta primeira versão da BNCC tenha causado um intenso e acirrado debate que envolveu historiadores de diversas áreas do conhecimento. As propostas inovadoras da Comissão que redigiu a Base foram alvo de pesadas críticas, fosse pelo método, fosse pelas escolhas temáticas, por exemplo, nos pareceres elaborados por profissionais da área, que incluíram importantes nomes da historiografia brasileira.

O parecer de Marieta de Moraes Ferreira6 ${ }^{6}$, por exemplo, critica a organização não cronológica da $1^{a}$ BNCC, a partir do seguinte argumento: a ausência de cronologia gera uma ausência de contexto e, portanto, um enfraquecimento na noção de processo histórico. Bem colocado pela historiadora, esse argumento se torna questionável, pelo menos em parte,

\footnotetext{
${ }^{6}$ Ver:

http://historiadabncc.mec.gov.br/documentos/relatoriosanaliticos/pareceres/Marieta_de_M oraes_Ferreira.pdf.
} 
quando na página seguinte a historiadora usa a Antiguidade e a Idade Média como exemplos. Ao apontar a exclusão desses temas por quase a totalidade da BNCC, a historiadora discute o quanto um aluno de terceiro ano do Ensino Médio ${ }^{7}$ teria problemas em lidar, simultaneamente, com a História Contemporânea da Globalização e conceitos básicos como o de "democracia". A grande questão é que esse comentário pode ser interpretado como um reflexo da tradição que lida com o Mundo Antigo como fundador de princípios que a modernidade expandiu.

\begin{abstract}
Várias ideias novas confluíram na construção da História Antiga como disciplina científica e muitas delas afetam seu ensino até os dias de hoje. [...] impulsionada pelo romantismo, a História Antiga tornou-se uma História de nações. [...] Para a maioria dos estudiosos, a História das nações europeias começava na História da nação grega. (GUARINELLO, 2013, p. 20).
\end{abstract}

Evidentemente, a leitura proposta pela historiadora é possível, entretanto ignora o fato de a "Antiguidade Clássica" ser uma construção renascentista (GUARINELLO, 2013, p. 19; LE GOFF, 2015, p. 25 - 31). Construção essa que possibilitou leituras posteriores, dentre elas as das revoluções às quais Marieta de Moraes Ferreira também se refere em seu parecer, como parte de uma História Contemporânea tributária dessa História Antiga. Dito de outra forma, a democracia que se pretendeu para Atenas é a leitura que uma época fez dos textos que nos restaram; uma época, por exemplo, que rejeitou propositalmente a Declaração dos Direitos da Mulher e da Cidadã $^{8}$ e desenvolveu, pouco depois, instituições inteiras ideologicamente construídas para atender às demandas de uma elite política com olhos voltados para um imperialismo justificado pelo culto ao ideal civilizacional dito "clássico" do qual aquelas elites supostamente descendiam: caso, por exemplo, dos museus (SOARES, 2011; DUFAL,

\footnotetext{
7 Aquele que teria maior contato com os temas, de acordo com uma "pequena menção" (BRASIL, [2015], p. 3) do texto da Base.

8 Ver: https://periodicos.ufsc.br/index.php/interthesis/article/viewFile/911/10852 .
} 
2018) ${ }^{9}$. Observar a cronologia talvez seja, de fato, uma maneira eficiente de ter em mente a existência de conexões entre os acontecimentos de diferentes tempos. Ainda assim, fica a questão: precisamos entender o Mundo Antigo como um passado fundador retomado posteriormente? Ou há um horizonte em que se entende que essa "Antiguidade" foi construída a partir de um momento específico e reinterpretada de acordo com a peculiaridade de cada época/região, como um instrumento de legitimação político-ideológico?

Outro parecer que vale a pena citar aqui é o de Pedro Paulo Funari ${ }^{10}$. No texto, o autor defende que o enfoque na história nacional dado pela BNCC prejudica a Educação histórica dos jovens na medida em que inviabiliza a estes um conhecimento universal, diversificado e amplo; estaria, assim, danificada a formação dos cidadãos brasileiros. O ponto em que Funari retorna constantemente é o da elitização de conhecimentos como História Antiga, Medieval, mesmo do Extremo Oriente, à medida em que esses saberes estariam sendo retirados da Educação Básica em detrimento de uma História do Brasil, único norte defendido pela Base como claramente conectado à realidade dos estudantes. O argumento de Funari perpassa exemplos como o dos Estados Unidos da América, que produz uma segregação intelectual na medida em que se enfoca a História nacional para a Educação Básica: enquanto a maioria da população tem uma noção limitada dos processos históricos mundiais, uma elite muito reduzida tem uma Educação que supera essas barreiras e se constitui intelectualmente muito melhor informada. Pedro Paulo Funari ainda comenta o quão importante é o conhecimento amplo como "única maneira de produzir um conhecimento crítico, não servil, sobre os usos do passado" (FUNARI, p. 2, 2016). Com essa fala, era de se esperar que um ponto marcado como fundamental, ao menos para a História Antiga, fosse a sua utilização frequente por um mundo Moderno/Contemporâneo em constante

\footnotetext{
${ }^{9}$ Incoerências entre as abordagens dos dois textos no que se refere à Grécia Antiga serão discutidas em outro momento, não sendo pertinentes neste trabalho. Demonstramos, contudo, o reconhecimento deste ponto.

10 Ver:

http://historiadabncc.mec.gov.br/documentos/relatoriosanaliticos/pareceres/Pedro_Paulo_ A._Funari.pdf
} 
construção, inclusive no momento de sua eleição como conhecimento válido e indispensável. O que ocorre logo em seguida é, contudo, bem diferente. A partir do argumento da necessidade de uma percepção universal das histórias humanas para uma boa Educação, Funari elenca os conteúdos que deveriam constar na BNCC; todo o conteúdo tradicionalmente considerado para a Educação Básica, com um único diferencial: as histórias da China e Índia Antigas. A reflexão do autor se baseia no seguinte ponto:

\begin{abstract}
Apenas a inclusão de uma perspectiva universal, que dê conta do repertório da tradição e inclua um inventário de diversidades, poderá resultar em uma educação menos excludente. Tal como está, contraria as políticas de estado de inclusão social e de inserção mundial, praticadas há tempo, e aprofundará as desigualdades (FUNARI, 2016, p. 3).
\end{abstract}

O início do parágrafo seguinte vem assim: "Sua reformulação deve, portanto, incluir, de forma explícita e detalhada, os conteúdos essenciais do repertório universal [...]" (FUNARI, 2016, p. 3).

Todo o parecer gira em torno da manutenção de uma Educação repleta de conteúdos indispensáveis, que não seja excludente ou omissa, embora ignore civilizações como a dos minóicos, micênicos, gauleses, celta. Até que ponto evitamos ser omissos talvez seja um ponto interessante a refletir em outro momento, contudo a questão máxima seja a seguinte: evitar ser omisso com a História Antiga não é reproduzir, mesmo que com uma nova roupagem, um discurso tradicional? Esse talvez seja o ponto mais questionável no parecer de Pedro Paulo Funari. Defender a ideia de um conhecimento universal que, entretanto, deve excluir alguns pontos em detrimento de outros não parece uma defesa da grande necessidade de os jovens conhecerem diferentes realidades históricas: a prática defendida aqui se assemelha muito mais a uma reprodução do discurso da continuidade e do alicerce da Civilização Ocidental, evitando compreender que o Ocidente eurocêntrico criou a si mesmo tomando emprestado o que se propôs ler nas culturas nomeadas Clássicas. Em momento algum esse tipo de reflexão surge, também, neste parecer. 
Outro documento que devemos analisar com extrema cautela é a carta de repúdio à BNCC publicado pelo Fórum dos Profissionais de História Antiga e Medieval ${ }^{11}$. Em um primeiro momento, questiona a existência de um currículo mínimo defendendo a necessidade de manter a autonomia dos professores, ao optar por procedimentos de aprendizagem e pesquisa de acordo com as demandas dos estudantes: o que a Base deveria estabelecer seria, portanto, uma série de "conceitos e habilidades a serem desenvolvidas pelos estudantes". O texto segue argumentando que a Base foi elaborada com ausência de diálogo e por uma comissão composta por profissionais pouco diversificados que não condiziam com a realidade acadêmica nacional. Enfatiza a falta de debates com a comunidade acadêmica e o quanto a

[...] consulta pública foi reduzida a sugestões para correções e acréscimos pontuais. [...] Consultas apressadas em escolas e secretarias de educação por todo país, poucos debates em universidades e associações científicas, além do engessado sistema de contribuições através da plataforma online criam somente a ilusória percepção de um diálogo, destinado apenas à legitimação de um processo antidemocrático (FÓRUM DOS PROFISSIONAIS DE HISTÓRIA ANTIGA E MEDIEVAL, 2016).

Logo em seguida, o ponto marcado é, contudo, a falta de pluralidade:

\begin{abstract}
Um processo construído desta maneira apenas poderia resultar em um documento com graves problemas de conteúdo. A falta de diversidade que caracterizou a seleção dos agentes envolvidos na elaboração da Base impediu a construção de um documento plural. O componente História acabou inteiramente subordinado a uma perspectiva nacionalista, tributária de uma concepção historiográfica do século XIX. Isto impede um ensino de História fundamentado em critérios mais amplos e cria dificuldades também para a abordagem dos próprios temas relativos à História do Brasil (FÓRUM DOS PROFISSIONAIS DE HISTÓRIA ANTIGA E MEDIEVAL, 2016).
\end{abstract}

Uma História que incluiria uma diversidade maior de assuntos é descrita, desta forma, como um caminho para possibilitar um melhor

\footnotetext{
${ }^{11}$ Ver: http://site.anpuh.org/index.php/bncc-historia/item/3127-carta-de-repudio-a-bnccproduzida-pelo-forum-dos-profissionais-de-historia-antiga-e-medieval.
} 
desenvolvimento intelectual das crianças e dos jovens da Educação Básica. Similar ao argumento de Pedro Paulo Funari, o texto da carta de repúdio segue adiante com novas considerações, criticando um posicionamento voltado à identidade nacional a partir de uma ideia de nação fixamente fundamentada na exclusão de um universo de fatos históricos que constituíram, para o aluno, um melhor arcabouço para ler o mundo. A História Antiga é citada no parágrafo seguinte:

\begin{abstract}
A Base, portanto, limita a pluralidade dos passados ao partir da centralidade da ideia de nação. O sintoma mais claro disto é a omissão de temas relativos a passados distantes, cuja análise permitiria aos estudantes refletirem acerca de experiências diversas daquelas em que estão diretamente envolvidos, tanto cronológica quanto geograficamente. Dessa forma, é igualmente empobrecedora, por exemplo, a exclusão de História Antiga e Medieval, baseada na falsa assunção de que só é possível pensar a Antiguidade e o Medievo sob o ponto de vista eurocêntrico. É necessário colocar essas histórias em uma perspectiva mais ampla, que inclua experiências anteriores ao século XVI, tais como a dos povos nativos das Américas, da África e de outras sociedades, para desta maneira permitir a construção de narrativas que justamente questionem o eurocentrismo (FÓRUM DOS PROFISSIONAIS DE HISTÓRIA ANTIGA E MEDIEVAL, 2016).
\end{abstract}

Não há como negar que a análise de diferentes realidades (históricas e/ou sociais) possibilita aos estudantes uma melhor apreciação sobre uma gama maior de mundos possíveis. Possivelmente seja este o momento em que o texto alcança, com clareza, um dos pontos centrais para o debate da História Antiga na sala de aula. Em contrapartida, argumentar que trabalhar a Antiguidade e o Medievo é possível com a ausência do eurocentrismo sem, contudo, buscar enfatizar o quanto a Antiguidade Clássica e uma Antiguidade Oriental, da mesma forma como uma Idade Média da Europa Setentrional, são conteúdos escolhidos a partir de algum critério, parece um contrassenso. Não se evidencia uma maneira não eurocêntrica de lidar com estes temas, ainda que consideremos isto possível. O que fica subentendido é que lidar com o Mundo Antigo (e que fique claro que seria melhor dizer um Mundo Antigo) apenas como mais um passado da História humana 
talvez seja um caminho. É possível que seja? A última frase da carta de repúdio foi escrita da seguinte maneira: "O enquadramento nacionalista do componente História da BNCC restringe os estudantes a uma narrativa histórica única."

Fica como questão pertinente o que significa essa restrição a uma narrativa histórica única. O documento se faz claro sobre a limitação de uma História pura e pretensamente nacionalista. Mas a simples inclusão dos temas referentes à Antiguidade não garante uma perspectiva não eurocêntrica, como o próprio documento aponta. A questão proposta é lidar com estes assuntos a partir de novas perspectivas, que não são, em momento algum, explicitadas no texto. Suponhamos, então, que uma perspectiva não eurocêntrica possível seja compreender que o Mundo Antigo é outro mundo e não um ponto inicial de uma linha única. Se retornarmos ao exemplo do conceito de "democracia" comentado anteriormente a partir da leitura do parecer de Marieta de Moraes Ferreira, este tipo de conteúdo se manteria trabalhado a partir de que noção? Permaneceria entendido como uma noção básica desenvolvida na Grécia (agora pensada como um outro mundo e não, simplesmente, o berço da civilização) que teria sido retomada com as revoluções burguesas, passando pela filosofia iluminista? Se a resposta for "sim", há realmente uma crítica ao eurocentrismo pelo simples fato de serem incluídas outras antiguidades e as realidades ameríndias no currículo, se no fim de tudo são os conceitos europeus que serão aprofundados (sendo estes muitas vezes entendidos como elaborados na Antiguidade)? No caso específico da História Antiga e, precisamente, na Antiguidade (nomeada) Clássica, não haveria maior precisão na ênfase do quanto esse passado foi eleito válido por razões específicas? E não seria insuficiente eleger outros passados a dividirem espaço com este, no intuito de diminuir o caráter valorativo deste conhecimento, sem, contudo, deixar de tomá-lo como um ponto de partida?

As formas de narrar o passado, as filosofias, os pensamentos políticos, foram interpretações de seus próprios mundos. Com isso pretendemos dizer que consta na habilidade do historiador, tão valorizada 
no texto das diferentes versões da $\mathrm{BNCC}^{12}$, muito mais decodificar momentos únicos do que apenas compreender continuidades; até mesmo uma união equilibrada de ambos. Se Tucídides teve acesso ao texto de Heródoto, contudo escreveu para a Atenas da Guerra do Peloponeso, enquanto Heródoto falou a uma Atenas no auge de seu poder ${ }^{13}$. Essa reflexão trata de dois autores dentro do mesmo século; pensemos agora sobre a leitura que o século XVIII fez dos textos elaborados mais de mil anos antes. O mundo dos iluministas, por exemplo, é muito diferente do de Heródoto e os dois, muito diferentes do nosso. Os marcos que buscamos no passado são similares àqueles buscados nos textos nomeados clássicos pelos intelectuais e estadistas de séculos anteriores. Constantemente são feitas escolhas, em meio a uma disputa, buscando argumentar sobre o que é mais ou menos importante de ser lembrado (e de que forma). Infelizmente, esse tipo de reflexão não apareceu nos pareceres e na carta de repúdio do Fórum de Profissionais de História Antiga e Medieval.

A ausência dessa análise no debate e nas críticas à BNCC pode ter determinado os resultados na produção das duas versões subsequentes, como veremos adiante no intuito de concluir nosso raciocínio.

A segunda versão da BNCC trouxe um tratamento diferente da proposta da primeira versão para a História nos anos finais do Ensino Fundamental. Vejamos a primeira frase no texto introdutório do componente curricular História nesse período da Educação Básica:

Nos anos finais do Ensino Fundamental ganha espaço o desenvolvimento dos conhecimentos necessários à lida com processos históricos de progressiva complexidade, exigindo maior capacidade de abstração, a começar pela mobilização do mundo da antiguidade clássica e medieval (BRASIL, 2016, p. 460).

Com uma citação inicial da Antiguidade Clássica (e gostaríamos de frisar o foco nessa Antiguidade "Clássica") e da Idade Média, o texto realiza

\footnotetext{
12 Vide a chamada "atitude historiadora" na terceira versão da BNCC (BRASIL, [2017], p. 348).

${ }^{13}$ Considerando, entretanto, que o nono livro de sua obra já é composto em meio à guerra da qual Tucídides trata (Hdt, IX, 73).
} 
um esforço para apaziguar as violentas reivindicações da comunidade acadêmica:

\begin{abstract}
A proposta é a de que esse esforço de afastamento do tempo presente seja facilitado pelo estudo da História do Brasil, e que a reflexão sobre o Brasil se faça sempre presente, ora de forma direta, ora indiretamente, integrando recursos de linguagem e procedimentos de pesquisa (BRASIL, 2016, p. 460).
\end{abstract}

Retornemos ao exemplo do conceito de "democracia". Quando um tema como esse surge na discussão em sala de aula, apenas lendo os dois trechos anteriores parece ficar nítido o quanto "democracia" pretende ser entendido como um conceito fundado no Mundo Antigo e apenas retomado, e aperfeiçoado, pelo Mundo Contemporâneo. Há um ar de continuidade no fluxo histórico, como se de fato houvesse uma espécie de herança histórica universal para o mundo ocidental no qual o Brasil está inserido. Como já comentamos, é uma leitura possível; mas, possivelmente, insuficiente para o tratamento da História Antiga. Permanece ausente qualquer reflexão sobre o quanto esses conceitos são escolhidos enquanto frutos de discursos específicos sobre momentos históricos, como o da Revolução Francesa. A maneira concisa e tradicional de lidar com os conteúdos na segunda versão da BNCC, oposta à tendência voltada à construção de conhecimentos socioculturais da primeira versão, é consequência direta disso.

Não surpreende que o primeiro tópico do $6^{\circ}$ ano seja "conhecer a história da Grécia Antiga, com ênfase no processo de surgimento da pólis e da Filosofia" e que o ponto seguinte seja "Reconhecer os conceitos de democracia e cidadania construídos na Grécia clássica e, em particular, em Atenas" (BRASIL, 2016, p. 462). A questão a que pretendemos nos debruçar não é à presença desses temas, por si só, mas em como a História Antiga é localizada na linha temporal para os alunos, bem como na construção de um entendimento sobre o caminho que se percorreu até chegarmos aqui. O texto da Base da segunda versão segue a cronologia tradicional. Mais que isso, podemos evidenciar o quanto se fortalece a percepção de um Mundo Antigo de legados quando, mais adiante, se insere no 90 ano a necessidade de "Conhecer os conceitos fundamentais da ordem 
liberal e democrática": uma vez que esta versão insere conteúdos a partir da Revolução Francesa, ao se falar de democracia se retoma um conhecimento prévio, a democracia de Atenas, sem em momento algum ser proposta qualquer reflexão a respeito do quão reinventada essa democracia foi, em meio a escolhas realizadas por uma junta revolucionária amparada em uma filosofia que leu os textos do Mundo Antigo e interpretou de acordo com sua época ${ }^{14}$. Podemos insistir, também, no quanto a filosofia iluminista tem uma interpretação própria dos textos antigos se compararmos às interpretações dos clérigos medievais dadas a esses textos, por exemplo, ou ainda às interpretações tão dissonantes realizadas pela historiografia dos séculos XIX e XX; o objetivo do Ensino Fundamental não é formar historiadores, mas pode ser o de formar indivíduos capazes de compreender que o passado e sua produção (intelectual, cultural, econômica...) podem ser lidos de diferentes formas e que a própria História pensada e ensinada é em si uma interpretação (e uma escolha) com historicidade própria. Além disso, seria conveniente no caso do ensino de História Antiga permitir aos alunos uma reflexão sobre os usos feitos de certos saberes por outros tempos, permitindo uma experiência de pensamento crítico plena; como é o caso do século XIX:

Participar dessa cultura ilustre, de difícil aprendizado, legitimava a superioridade das elites, na Europa e no Brasil. Produzia, além disso, uma memória do 'Ocidente', uma identidade 'ocidental', que explicava e justificava o domínio dos países capitalistas, mais desenvolvidos tecnologicamente, sobre o restante do globo $^{15}$ (GUARINELLO, 2013, p. 27).

\footnotetext{
${ }^{14} \mathrm{O}$ que talvez fuja um pouco da indicação dada pelo texto introdutório sobre o Ensino Fundamental II que elenca como eixo de formação "Ética e pensamento crítico" (p. 461), mas esteja alinhada à mencionada "lida com processos históricos de progressiva complexidade, exigindo maior capacidade de abstração, a começar pela mobilização do mundo da antiguidade clássica e medieval" (p. 460), consideração que dá peso à cronologia como uma espécie de natureza do estudo de História e que, dessa forma, mantém uma lógica linear de produções de alicerces para construções mais complexas que vem com o passar do tempo.

15 Por "restante do globo" entenda-se que o historiador se refere ao neocolonialismo empregado na África.
} 
Em resumo, as críticas pesadas à BNCC surtiram algum efeito, sem dúvida - ao que parece, o efeito que se desejava, ao menos no que tange a História Antiga -, porém constar em um currículo mínimo obrigatoriamente é, então, suficiente e eficiente para o ensino a respeito do Mundo Antigo? Talvez seja difícil responder ou propor qualquer alternativa. Se pensarmos que a terceira versão da BNCC contém em seu texto a mesma organização cronológica tradicional, incluindo apenas uma singela preocupação com a importância de discutir a invenção de uma Antiguidade "Clássica" (BRASIL, [2017], p. 370-371), não parece muito diversificada a maneira de lidar com a História senão por uma vestimenta mais adequada ao nosso momento; o esqueleto, infelizmente, permanece o mesmo; graças aos "pressure groups" aos quais Arnaldo Momigliano já se referia em 1975, aqueles que simultaneamente admitem algum esquecimento de uma "herança" celta, germânica, árabe, mas que de forma alguma permite o esquecimento de um débito para com gregos, romanos e [talvez não tanto na conjuntura específica que tratamos neste trabalho] com os judeus (MOMIGLIANO, 2012, p. 11) ${ }^{16}$.

A terceira versão contém em seu texto introdutório para os anos finais do Ensino Fundamental uma divisão de três procedimentos básicos. Um primeiro que "implica o uso de uma forma de representação, a cronológica, constituída por meio de uma seleção de eventos históricos consolidados na cultura historiográfica" (BRASIL, [2017], p. 367). Não podemos deixar de notar que a cronologia surge agora nomeada com total evidência no texto introdutório. Enquanto os outros dois procedimentos são, respectivamente, "escolha de fontes e documentos" (BRASIL, [2017], p. 369) e a "escolha de duas ou mais proposições que analisam um mesmo tema ou problema por ângulos diferentes" (BRASIL, [2017], p. 369), o primeiro procedimento insiste que:

As mesclas entre as histórias da América, da África, da Europa e de outros continentes apresentam diferentes níveis de elaboração ao serem trazidos à tona rupturas, permanências e movimentos de população e mercadorias,

\footnotetext{
${ }^{16}$ Aqui é importante destacar, contudo, que o próprio Momigliano estava embutido nesse processo que comenta em tom de denúncia sarcástica.
} 
mediados por distintas estruturas econômicas, sociais, políticas e culturais (BRASIL, [2017], p. 368).

Ao falar em permanências e rupturas ligadas à História do Brasil, pelo menos no que tange ao ensino de História Antiga, é admitida uma linha entre um Mundo Antigo muito distante e um país latino-americano sem, contudo, analisar com cautela a elaboração dessa linha. Se levarmos em conta que a terceira versão escorrega na direção do questionamento propondo "Discutir o conceito de Antiguidade Clássica, seu alcance e limite na tradição ocidental", ela retoma seu curso concluindo "assim como os impactos sobre outras sociedades e culturas" (BRASIL, [2017], p. 371). Algum avanço, sem dúvida, mas sutil, senão tímido e, no mínimo, ambivalente: permite ao professor questionar seus alunos à moda de Sócrates sobre uma apropriação moderna (com uma lente moderna) de um passado muito distante e distinto; mas permite, também, que se retome a velha noção de que o alicerce chegou até nós, graças ao esforço de recuperação da Renascença que valorizou a chamada cultura greco-romana e trouxe, com o Humanismo, conceitos que são presentes até hoje, desconsiderando a polissemia de conceitos historicamente datados ${ }^{17}$, mas, acima de tudo, mantendo uma percepção de tempo histórico constituído por continuidades e retomadas.

Um caminho possível seria insistir no fato de a Antiguidade "Clássica", em especial os aspectos da cultura grega, ter sofrido uma extenuante apropriação pela intelectualidade contemporânea, desde meados do século XVIII, por meio da percepção de que a civilização é a categoria fundamental definidora das sociedades, como uma escala evolutiva na qual está implicitamente inserido um critério valorativo: há as diversas civilizações; as mais e as menos desenvolvidas e, em algum sentido, sempre as mais ou menos semelhantes à Grécia "Clássica", portanto, mais ou menos bárbaras, respectivamente (DUFAL, 2018). Dito de outra forma, explorar aquilo que esteve presente no cerne mesmo da formação da historiografia contemporânea e que estabeleceu o estudo

\footnotetext{
17 Relembramos aqui, por exemplo, a discussão elaborada por Reinhart Kosseleck a respeito do conceito de democracia, que comentamos um pouco acima (KOSSELECK, 2006, p. 107).
} 
cronológico, enviesado pela noção de herança, da História de algumas sociedades humanas bem selecionadas. Os critérios de seleção são em si um excelente material didático a ser discutido.

Lembramos, é claro, que nosso trabalho está exclusivamente voltado para o ensino de História Antiga e que nossa preocupação aqui é, essencialmente, questionar que tipo de ensino se quer: verdadeiramente crítico ou apenas (pós-)modernizado? O ensino de História Antiga, se tão defendido como fundamental a um desenvolvimento intelectual mais plural (e acreditamos nisso), vai, contudo, parar somente na busca de manter seu lugar no $6^{\circ}$ ano do Ensino Fundamental, ou pretende atingir um ponto em que será entendido, não apenas como o passado que nos deixou uma herança, mas como o passado que foi também buscado, ao longo de diferentes momentos históricos, como legitimação político-ideológica, intelectual, religiosa, social e cultural? Se a primeira versão da BNCC tem um mérito fundamental, foi o de tentar romper com a tradição. As críticas despejadas sobre ela, que tinham a chance de se aproximar de novas discussões e permitir um novo enfoque para certos conteúdos, apenas mantiveram o lugar reservado da Grécia Antiga nas turmas de $6^{\circ}$ ano e uma concepção de História quase tão tradicional quanto a de algumas décadas atrás. Evidentemente houve resultados positivos em alguns pontos das novas versões da BNCC (para o ensino de História Antiga). Aparentemente, com limitações.

\section{Referências}

BRASIL. Ministério da Educação. Base Nacional Comum Currícular. [2015]. Disponível em:

http://www.educacao.mppr.mp.br/arquivos/File/publicacoes/mec/bncc_apre sentacao_2015.pdf. Acesso em: 25 maio 2017.

BRASIL. Ministério da Educação. Base Nacional Comum Currícular: proposta preliminar: segunda versão. 2016. Disponível em:

http://historiadabncc.mec.gov.br/documentos/bncc-2versao.revista.pdf. Acesso em: 25 maio 2017.

BRASIL. Ministério da Educação. Base Nacional Comum Currícular: educação é a base. [2017]. Disponível em: 
https://s3.amazonaws.com/cenpec-educacaoeparticipacao-producao/wpcontent/uploads/bncc_publicacao.pdf. Acesso em: 25 maio 2017.

DUFAL, Blaise. Le fantasme de la perfection originelle: la grèce antique comme matrice du modèle civilisationnel. Cahiers Mondes anciens, Paris, v. 9, n. 11, p. $1-25,2018$.

FÓRUM DOS PROFISSIONAIS DE HISTÓRIA ANTIGA E MEDIEVAL. Carta de repúdio à base nacional comum curricular de história. Rio de Janeiro, 2016. Disponível em: http://site.anpuh.org/index.php/bncc-historia/item/3127carta-de-repudio-a-bncc-produzida-pelo-forum-dos-profissionais-dehistoria-antiga-e-medieval. Acesso em: 28 maio 2017.

FUNARI, Pedro Paulo A. A história em sua integridade: a propósito da Base Nacional Comum Curricular. 2016. Disponível em:

http://historiadabncc.mec.gov.br/documentos/relatoriosanaliticos/pareceres /Pedro_Paulo_A._Funari.pdf. Acesso em: 28 maio 2017.

GUARINELLO, Norberto Luiz. História antiga. São Paulo: Contexto, 2013.

KOSSELECK, Reinhart. Futuro passado. Rio de Janeiro: Contraponto, 2006.

LE GOFF, Jacques. A história deve ser dividida em pedaços? São Paulo: Editora Unesp, 2015.

MOMIGLIANO, Arnaldo. Essays in ancient and modern historiography. Chicago: Chicago University Press, 2012.

SOARES, Bruno C. Brulon. O rapto das musas: apropriação do mundo clássico na invenção dos museus. Anais do Museu Histórico Nacional, Rio de Janeiro, v. 43, p. 41-65, 2011. 